\title{
Intelligent Fire Extinguisher System
}

\author{
Poonam Sonsale $^{1}$, Rutika Gawas ${ }^{2}$, Siddhi Pise ${ }^{3}$, Anuj Kaldate \\ ${ }^{1}$ (Computer Engineering,Padmabhooshan Vasantdada Patil Institute Of Technology/Pune university,India) \\ ${ }^{2}$ (Computer Engineering,Padmabhooshan Vasantdada Patil Institute Of Technology/Pune university,India) \\ ${ }^{3}$ (Computer Engineering,Padmabhooshan Vasantdada Patil Institute Of Technology/Pune university,India) \\ ${ }^{4}$ (Computer Engineering,Padmabhooshan Vasantdada Patil Institute Of Technology/Pune university,India)
}

\begin{abstract}
The multisensor fire-detection algorithm is one of the current important issues in the field of firedetection systems for intelligent buildings. This paper proposes an adaptive fusion algorithm for fire detection, and uses a smoke sensor, flame sensor, and temperature sensor to detect fire incident. In reality, the phenomenon of the fire incident may have smoke, flame, and high temperature situations. However, these signals may happen simultaneously or sequentially. We develop an intelligent multisensor based security system that contains a fire fighting system in our daily life. The security system can detect abnormal and dangerous situation and notify us. First, we design a firefighting system with extinguisher for the intelligent building. We design the fire detection system using sensors in the fire fighting system, and program the fire detection and fighting procedure using sensor based method. Finally, we implement the fire detection system using fire fighting system.
\end{abstract}

Keywords: ADC, Device Control, Fire Fighting System, Sensors, Sprinklers.

\section{Introduction}

Intelligent buildings are expected to be safer, convenient, and efficient living environments for society in the 21 st century. An intelligent building system (IBS) is integrated by many services and subsystems. One of the most important subsystems is the fire-detection function system in an intelligent building. [2] The purpose of our project "Intelligent Fire Extinguisher System" is to extinguish a flame in a certain amount of time. Our system detects the fire location and tries to extinguish the fire with the help of sprinklers. As begin a "Intelligent System" it cut offs the electricity of area where fire has been caught and starts the sprinklers only of that area.

\subsection{Forward reference}

\section{Literature Survey}

Today, fire companies are both paid and volunteer. The technology is far more advanced than in the earlier times. Fire fighters wear full heat resistant gear and are equipped with oxygen tanks and high pressure fire houses. Companies such as AFT (Advanced Fire fighting Technology) are working to make fire fighting safer and more effective with low-pressure Water Mist and CAFS (compressed air foam systems).

The London based company, Qinetiq has been commissioned to deploy a team of three systems to respond to fires where Acetylene gas is present.[4] When this gas is present in canisters, fire fighters are forced to sit back and watch the fire until after the gas has exploded.

The three systems each have a specific job and can keep the human fire fighters out of danger. Other companies, Brazilian based ARMTEC, Las Vegas based InRob and iSystem, inventors of the Roomba, have also been developing system technology for firefighting. The technology is far from perfect however and will be continuously developed in the coming years.

\subsection{Backward reference}

The history of fire fighting can be dated back to the times of Ancient Egypt where hand pumps were used to fight fires. However, it wasn't until 1699 in France, that fire fighting became modernized. Here, François du Mouriez du Périer introduced the first commercially provided fire pumps to the City of Paris. In the 1800 's helmets were introduced to protect the fire fighters.

The first steam powered fire engine was used in Cincinnati Ohio on April 1, 1853.[4] This was also the first full time paid fire department in the United States. However, in 1907, the first internal combustion engine fire engines were developed. These lead to the extinction of the steam engine fire engine by 1925 .

\section{Existing System}

The Existing system for fire detection and extinguishing lacks intelligence. The existing systems major drawback is that if the fire is small and limited to a small area, still the sprinklers are on for the whole area, this results in waste of water. 


\subsection{Architecture}

\section{Proposed System}

Consider the setup of fire extinguisher system that can help us to locate the place where the fire is origin. And using this system we can control the sprinkler system and also we can control the electricity.

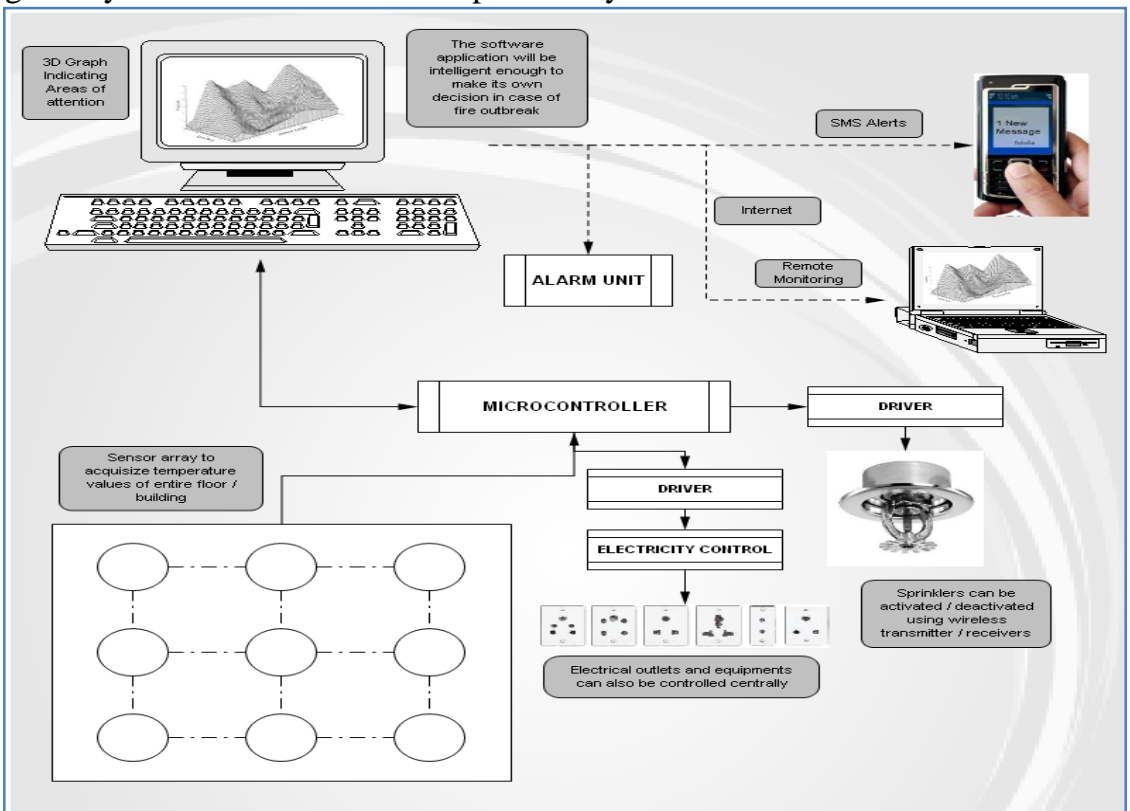

Fig. System architecture

\subsection{System Features}

- Intelligent fire detection and suppressions

- Locate the position of fire origin.

- Effective power control of electricity.

- Reporting through the sms or email.

- $\quad$ Effective usage of water supply

\section{Future Scope}

Future expansion that we are considering after this project is to provide even more functionality with our system. One example can be integrating our intelligent fire fighting system into a moving system (robot) to assist in the dangerous jobs that fire fighters encounter every day. However, that will be a separate project and we will focus on what we've proposed in this document.

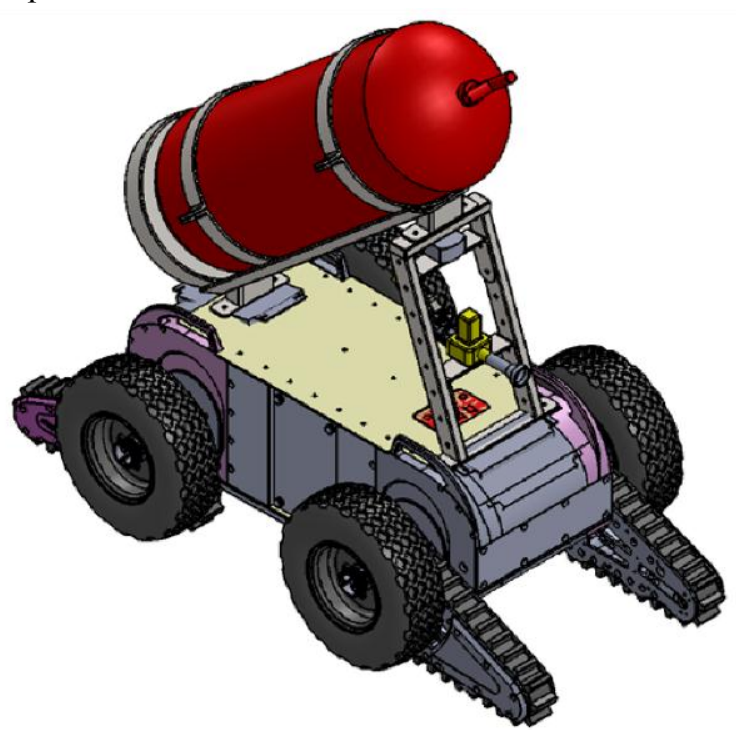

Fig. fire fighting robot 


\section{Conclusion}

The conclusion is to provide security of home, laboratory, office, factory and building is important to human life. We develop an intelligent multisensory based security system that contains a fire fighting system in our daily life. We design the fire detection system using sensors in the system, and program the fire detection and fighting procedure using sensor based method.

\section{Acknowledgements}

I would like to show my greatest appreciation to Prof. Hema kumbhar and Prof. Y.B.Gurav without their encouragement and guidance, this paper would not have materialized. The guidance and support received from all the Faculty of Department/Institute and classmates who contributed, was vital for the success of the project. I am grateful for their constant support and help.

\section{References}

[1] Design of Intelligent Fire Extinguishing System of Interior Large Space"-E-Product E-Service and E-Entertainment (ICEEE), 2010 International Conference.

[2] Voice Operated Intelligent Fire Extinguisher Vehicle, March 29, 2013.

[3] "Wireless Intelligent Fire Fighting Systems Software Platform R\&D"- Internet of Things (iThings/CPSCom), 2011 International Conference on and $4^{\text {th }}$ International Conference on Cyber, Physical and Social Networking

[4] "Develop a Multiple Interface Based Fire Fighting System"- Mechatronics, ICM2007 $4^{\text {th }}$ IEEE -International Conference Date of Conference: 8-10 May 2007

[5] Design of Gas fire-extinguishing control panel based on multi-sensor information fusion Multimedia Technology (ICMT), 2011 International Conference 10-12 Aug. 2010 